\title{
Adjunctive therapy for glucose control in patients with type I diabetes
}

This article was published in the following Dove Press journal: Diabetes, Metabolic Syndrome and Obesity:Targets and Therapy

\section{Kira Harris ${ }^{1,2}$ \\ Cassie Boland ${ }^{1,3}$ \\ Lisa Meade ${ }^{1,4}$ \\ Dawn Battise ${ }^{1,5}$}

'Pharmacy Practice Faculty, Wingate University School of Pharmacy, Wingate, NC, USA ${ }^{2}$ Clinical Pharmacy Specialist - Novant Health Family Medicine Residency Program, Cornelius, NC, USA; ${ }^{3}$ Clinical Pharmacy Specialist - Novant Health Cotswold Family Medicine Arboretum, Charlotte, NC, USA; ${ }^{4}$ Clinical Pharmacy Specialist Piedmont HealthCare Endocrinology, Statesville, NC, USA; ${ }^{5}$ Clinical Pharmacy Specialist - Cabarrus Family Medicine - Harrisburg, Harrisburg, NC, USA
Correspondence: Kira Harris

Wingate University School of Pharmacy, 515 North Main St, Wingate, NC 28I74, USA

Tel +l 7042338965

Fax +I 7042338332

Email k.brice@wingate.edu
Abstract: Type 1 diabetes mellitus (T1DM) is characterized by relative or absolute insulin deficiency. Despite treatment with insulin therapy, glycemic goals are not always met, and insulin therapy is sometimes limited by adverse effects, including hypoglycemia and weight gain. Several adjunctive therapies have been evaluated in combination with insulin in patients with T1DM to improve glycemic control while minimizing adverse effects. Pramlintide, an amylin analog, can improve glycemic control, primarily through lowering postprandial blood glucose levels. Patients may experience weight loss and an increased risk of hypoglycemia and require additional mealtime injections. Metformin provides an inexpensive, oral treatment option and may reduce blood glucose, especially in overweight or obese patients with minimal risk of hypoglycemia. Metformin may be more effective in patients with impaired insulin sensitivity. Glucagon-like peptide-1 receptor agonists reduce primarily postprandial blood glucose and insulin dose and promote weight loss. They are expensive, cause transient nausea, may increase risk of hypoglycemia and require additional injections. Sodium-glucose transport-2 inhibitors improve glycemic control, promote weight loss and have low risk of hypoglycemia with appropriate insulin adjustment; however, these agents may increase the risk of diabetic ketoacidosis in patients with T1DM. Patient-specific characteristics should be considered when selecting adjunctive therapy for patients with T1DM. Close monitoring, insulin dose adjustments and patient education are all important to ensure safe and effective use of these agents.

Keywords: type 1 diabetes mellitus, metformin, amylin, sodium-glucose cotransporter 2 inhibitors, glucagon-like peptide-1 receptor agonists, dipeptidyl-peptidase 4 inhibitors

\section{Introduction}

Type 1 diabetes mellitus (T1DM) is characterized by reduced insulin secretion or absolute insulin deficiency as a result of autoimmune beta-cell dysfunction. ${ }^{1}$ Standard of care for T1DM management is intensive insulin therapy, although this only partially addresses the inappropriate glucagon release due to abnormal alpha-cell function. ${ }^{1,2}$ Intensive glucose control can decrease the risk of microvascular and macrovascular complications in T1DM, ${ }^{3-5}$ but often causes undesirable adverse effects (AEs), including increased risk of hypoglycemia, weight gain, higher insulin doses and frequent injections..$^{5}$ Despite advances in insulin and its administration, patients with T1DM continue to have difficulty achieving optimal glucose control. ${ }^{5}$ As a result, the evaluation of adjunctive therapies for patients with T1DM is warranted. ${ }^{5}$

Several adjunctive treatments have been studied to determine potential benefits in T1DM based on their mechanisms of action and AE profiles in type 2 diabetes mellitus (T2DM). ${ }^{1}$ Pramlintide is an amylin analog and currently the only US Food 
and Drug Administration (FDA)-approved adjunctive therapy for T1DM. ${ }^{6}$ Although it is associated with weight loss and glucagon inhibition, pramlintide use is limited because of administration and AEs. Metformin, a biguanide, is recommended by the American Diabetes Association (ADA) in obese patients with T1DM and currently utilized more frequently than pramlintide in these patients $(6 \%$ versus $2 \%$, respectively). ${ }^{1,7}$ Metformin may demonstrate benefits on insulin dose and weight without increasing hypoglycemia risk. ${ }^{1,2,8}$ Incretin mimetics, including glucagon-like peptide-1 receptor agonists (GLP-1 RAs) and dipeptidyl-peptidase-4 inhibitors (DPP-4 inhibitors), have been associated with decreased glucagon secretion, and GLP-1 RAs also promote weight loss. ${ }^{2}$ Sodium-glucose transporter-2 (SGLT2) inhibitors impair renal glucose reabsorption in an insulin-independent manner and have also been studied in T1DM. ${ }^{2}$ This review will evaluate the efficacy and safety of these non-insulin adjunctive therapies for patients with T1DM.

PubMed (1966-December 2017) and Ovid (1946December 2017) were used to search Medline using the keywords type 1 diabetes mellitus, pramlintide, metformin, glucagon-like peptide-1 receptor agonist, exenatide, liraglutide, dulaglutide, albiglutide, lixisenatide, semaglutide, sitagliptin, saxagliptin, linagliptin, alogliptin, vildagliptin, canagliflozin, dapagliflozin, sotagliflozin and empagliflozin. Abstracts presented at the scientific and clinical sessions of the ADA and the American Association of Clinical Endocrinologists were also reviewed. The references of published articles identified were examined for additional studies appropriate for the review. Publications involving animal subjects, healthy patients or patients with type 2 diabetes were excluded. Publications evaluating clinical outcomes related to blood glucose (BG), hemoglobin A1c (A1c) or weight in patients with T1DM were included. Of 240 abstracts identified, the most common reasons for exclusion were the inclusion of healthy patients or patients with T2DM or the evaluation of intermediate outcomes.

\section{Pramlintide}

\section{Mechanism of action and clinical effects}

Amylin is cosecreted with insulin from the pancreatic $\beta$-cells and inhibits postprandial glucagon secretion, slows gastric emptying and increases satiety. Patients with T1DM have a deficiency of insulin and amylin. Poor solubility and problems with aggregation prevent use of native amylin. Pramlintide, approved by the FDA in March 2005, is a synthetic analog of amylin. Both amylin and pramlintide have similar molecular structures and bind to amylin receptors. Clinical benefits of pramlintide include decreasing postprandial glucose and improving A1c without weight gain.

\section{Clinical evaluation}

The safety and efficacy of pramlintide have been evaluated in multiple studies, which are summarized in Table 1. In a randomized study with an open-label extension, pramlintide improved long-term glycemic control without producing weight gain or increasing the incidence of hypoglycemia. This double-blind, multicenter study included 480 patients with T1DM randomized to receive pramlintide $30 \mathrm{mcg}$ or placebo with insulin prior to meals and a bedtime snack (four times a day). At week 20 of the 52-week trial, the dose was increased to $60 \mathrm{mcg}$ if the change in A1c was $<1 \%$ from baseline. The Alc reduction at week 13 was $0.67 \%$, which was statistically significant $(P<0.0001)$ compared to placebo. Change in A1c from baseline to week 52 was $-0.39 \%$ in the pramlintide group and $-0.12 \%$ in the placebo group $(p=0.0071)$. Three hundred forty-two patients completed the first 52 weeks and $69 \%$ continued in the open-label extension. Patients in the open-label portion were started on pramlintide $30 \mathrm{mcg}$ and could increase to $60 \mathrm{mcg}$. The total daily insulin dose (TDID) increased by $2.3 \%$ in the pramlintide group and $10.3 \%$ in the placebo group at week $52(p=0.0176)$. Total daily insulin was not followed for the extension part of the study. The openlabel extension (weeks 52-104) showed that the A1c reduction was maintained. There was a slight decrease in body weight in the pramlintide group $(0.5 \mathrm{~kg})$ and an increase in the placebo group $(1.0 \mathrm{~kg})$ at the end of 52 weeks $(p>0.05)$. Severe hypoglycemia, defined as requiring the assistance of another person, was the same across all groups. Nausea occurred more frequently in the first 2 weeks of therapy and was the most common reason for withdrawal $(7.4 \%$ in the pramlintide group and $1.7 \%$ in the placebo group) from the study (no $p$ value reported). ${ }^{9}$

Another randomized clinical trial evaluated glycemic control and weight after 1 year of therapy with pramlintide $60 \mathrm{mcg}$ dosed three or four times a day (TID or QID). The double-blind, placebo-controlled, parallel-group study included 651 patients with T1DM. A fourth treatment arm (90 mcg TID) was excluded from the efficacy analysis but included in the safety analyses. Consistent with other trials, nausea was the most common $\mathrm{AE}$ and more patients withdrew in the treatment groups (TID 19.5\% and QID 13.7\%) compared to placebo (3.9\%). Reduction in A1c at 52 weeks for the TID group was $0.29 \%(p<0.011)$ and $0.34 \%(p<0.001)$ for the QID group compared to $0.04 \%$ reduction with placebo. Three times more patients receiving pramlintide reached an 
Table I Summary of clinical trials for pramlintide in patients with TIDM

\begin{tabular}{|l|l|l|l|l|}
\hline Study & Duration (weeks) & Number of patients & Pramlintide regimen & Results \\
\hline Whitehouse et al, ${ }^{9} 2002$ & 52 & 480 & $\begin{array}{l}\text { Placebo } \\
30-60 \mathrm{mcg} \text { QID }\end{array}$ & $\begin{array}{l}\text { Alc reduction } \\
\text { Weight loss }\end{array}$ \\
\hline Ratner et al, ${ }^{10} 2004$ & 52 & $65 I$ & $\begin{array}{l}\text { Placebo } \\
60 \mathrm{mcg} \text { TID } \\
60 \mathrm{mcg} \text { QID } \\
90 \mathrm{mcg} \text { TID }\end{array}$ & $\begin{array}{l}\text { Alc reduction } \\
\text { Weight loss }\end{array}$ \\
\hline Ratner et al, ${ }^{11} 2005$ & 26 & 477 & $\begin{array}{l}\text { Placebo } \\
30-60 \mathrm{mcg} \text { TID or QID }\end{array}$ & $\begin{array}{l}\text { Alc reduction } \\
\text { Weight loss } \\
\text { Decrease in insulin use }\end{array}$ \\
\hline Edelman et al, ${ }^{12} 2006$ & 29 & 296 & $\begin{array}{l}\text { Placebo } \\
\text { I5-60 mcg TID-QID }\end{array}$ & $\begin{array}{l}\text { Same Alc reduction in both placebo and } \\
\text { pramlintide } \\
\text { Reduction in postprandial excursions } \\
\text { Weight loss } \\
\text { Decrease in insulin use }\end{array}$ \\
\hline Levetan et al, ${ }^{14} 2003$ & 6 & 18 & $\begin{array}{l}\text { Decrease in hyperglycemia and increase in } \\
\text { euglycemia } \\
\text { Decrease in insulin use }\end{array}$ \\
\hline
\end{tabular}

Abbreviations: TIDM, type I diabetes mellitus; TID, 3 times daily; QID, 4 times daily; AIc, hemoglobin Alc.

A $1 \mathrm{c}$ of $<7 \%$ as compared to placebo. In addition, the average insulin use decreased in the TID group by $3 \%$ and by $6 \%$ in the QID group with no change in the placebo group (no $p$ value reported). Body weight decreased $0.4 \mathrm{~kg}$ in the TID $(p<0.027)$ and QID $(p<0.040)$ groups and the placebo group experienced $0.8 \mathrm{~kg}$ weight gain. Nausea occurred within the first 4 weeks of therapy but improved with continued use. Unlike other studies, investigators could reduce the pramlintide dose to $30 \mathrm{mcg}$ for 2 weeks to help with the nausea but then patients had to go back to the $60 \mathrm{mcg}$ dose. ${ }^{10}$

A pooled analysis of three long-term clinical trials showed that pramlintide may help patients with T1DM and an A1c close to target $(7 \%-8.5 \%)$ reach glycemic goals without increasing the risk of severe hypoglycemia and weight gain. Of 1717 patients enrolled in the three studies, 477 (281 on pramlintide and 196 placebo) met the criteria of A1c between $7 \%$ and $8.5 \%$. Patients received 30 or $60 \mathrm{mcg}$ of pramlintide TID or QID or placebo. Most patients were on multiple daily injections (MDI) with only 17 patients using continuous subcutaneous insulin infusion (CSII). The change in A1c was greater during the first 8 weeks of therapy $(0.4 \%$ reduction in pramlintide and no change in the placebo group), but slowly increased in weeks 8-26. A1c change from baseline to week 26 was $-0.16 \%(p=0.0009)$ in the pramlintide group and $0.1 \%$ increase in the placebo group. The placebo-corrected reduction in body weight from weeks 4 to 26 averaged 1.8 $\mathrm{kg}(p<0.0001)$. Insulin use declined in the pramlintide group by $4 \%$ and increased in the placebo group by $3 \%$. Rates of severe hypoglycemia were higher in the pramlintide group during the first 4 weeks of therapy. However, the overall event rate per subject for severe hypoglycemia was 1.40 in the pramlintide group and 1.86 in the placebo group. Nausea was more common during the first 4 weeks of therapy ( $40 \%$ in the pramlintide group compared to $6 \%$ in the placebo group), but leveled out during weeks $4-26$ (9\% in the pramlintide group and $6 \%$ in the placebo group). ${ }^{11}$

Edelman et al demonstrated that dose escalation with pramlintide in addition to mealtime insulin reduction during the initiation phase was safe and effective. This study included 296 patients with T1DM using MDI or CSII. The starting dose for pramlintide was $15 \mathrm{mcg}$ and was titrated by $15 \mathrm{mcg}$ weekly to a maximum of $60 \mathrm{mcg}$. Insulin dose was decreased $30 \%-50 \%$. Patients in the pramlintide and placebo group experienced a $0.5 \%$ reduction in $\mathrm{A} 1 \mathrm{c}$, but the pramlintide group experienced a significant decrease in postprandial glucose levels $(-175 \pm 40 \mathrm{mg} / \mathrm{dL})$ compared to placebo $(-64 \pm 38 \mathrm{mg} / \mathrm{dL})$ after 29 weeks. The TDID decreased by $12 \%$ in the pramlintide group and increased by $1 \%$ in the placebo group. The change in weight was significant for the pramlintide group, whereas the placebo group gained weight. Nausea was more common in the pramlintide group and severe hypoglycemia was the same for both groups. This study concluded that dose escalation with mealtime insulin reduction decreased nausea and the risk of hypoglycemia. ${ }^{12} \mathrm{~A}$ retrospective analysis of this study reported higher patient treatment satisfaction with pramlintide regardless of insulin delivery method (MDI or CSII). The majority of patients agreed or strongly agreed that pramlintide provided benefits that were worth the extra injections. ${ }^{13}$ 
A small study evaluated the use of pramlintide $30 \mathrm{mcg}$ TID in 18 patients with T1DM treated with CSII. Continuous glucose monitoring (CGM) showed that after 4 weeks of treatment there was an $11 \%$ decrease in hyperglycemic fluctuations $(>140 \mathrm{mg} / \mathrm{dL})$ and a $9 \%$ increase in time in the euglycemic range $(80-140 \mathrm{mg} / \mathrm{dL})$. In addition to decreasing postprandial glucose, pramlintide also significantly decreased glucagon and triglyceride excursions $(p<0.05){ }^{14}$

Most Phase III trials were completed in a general practice setting, but the dose escalation study was conducted at sites with more experience titrating insulin. ${ }^{15}$ Also, initially, pramlintide was only available in a vial and doses (in micrograms) were converted to units so that an insulin syringe could be used for delivery. This dosing was complicated for patients and providers. In three studies, there was a documented increase in A1c after an initial reduction. The increase in A1c started at weeks 8, 13 and 26. ${ }^{9-11}$ Decreased patient compliance with vial and syringe may contribute to the slow increase in A1c levels. Finally, two Phase III clinical trials and the pooled analysis study used fixed doses of pramlintide and insulin, so the incidence of nausea and hypoglycemia was much higher. The recommendation to titrate pramlintide and reduce insulin was not documented until the dose escalation study.

\section{Adverse effects}

\section{Nausea}

The most common AEs in Phase III clinical trials were nausea, anorexia, vomiting and headache. Nausea was defined as mild or moderate in intensity and did not interfere with daily activities or require treatment., ${ }^{9,10,12}$ Nausea is dose dependent and more common in the first 4-8 weeks of therapy. Some earlier clinical trials did not allow dose titration and, therefore, the frequency of nausea and the number of study withdrawals were much higher. Starting pramlintide with one meal a day and titrating to three meals a day may reduce nausea. Initiating pramlintide with the evening meal also allows patients to be home if nausea does occur. ${ }^{16}$ Nausea may also increase the risk of hypoglycemia because of less food intake. ${ }^{15}$ The dose escalation study showed about a $1.4 \%$ withdrawal because of nausea compared to about $9 \%$ for other clinical trials. About $70 \%$ of the 142 patients on pramlintide reached the max dose of $60 \mathrm{mcg}$.

\section{Hypoglycemia}

Pramlintide without concomitant insulin does not cause hypoglycemia, but when used with insulin it does increase the risk of and carries a black box warning for severe hypoglycemia in patients with T1DM. The risk of hypoglycemia is the highest 2-3 hours following an injection. Severe hypoglycemia (requiring assistance from another person) was more frequent during the first 4-6 weeks of therapy. ${ }^{9,10}$ Rates of hypoglycemia were higher in some of the early clinical trials because patients were not allowed to adjust doses of mealtime insulin. The rate of severe hypoglycemia was similar to placebo in the dose escalation study, which allowed a 30\%-50\% reduction in mealtime insulin when pramlintide was initiated. Dosing pramlintide before the meal and dosing mealtime insulin 5-15 minutes after the meal allow patients to adjust insulin doses based on actual carbohydrates consumed. ${ }^{12}$

\section{Weight loss}

In the Diabetes Control and Complications Trial, intensive insulin therapy was associated with an average of $4.75 \mathrm{~kg}$ more weight gain than in the conventional treatment group. Lipid levels and blood pressure increased with the weight gain and were similar to patients with insulin resistance. ${ }^{17} \mathrm{~A} 1 \mathrm{c}$ improvement in the trials with pramlintide was associated with a $0.4-1.3 \mathrm{~kg}$ reduction in weight. ${ }^{9,10,12}$ The weight loss associated with pramlintide is independent of the nausea. ${ }^{18}$ In one of the clinical trials, patients were stratified based on baseline body mass index (BMI). Patients with a BMI $\geq 27 \mathrm{~kg} / \mathrm{m}^{2}$ lost more weight compared to patients with a BMI $23-27 .{ }^{10}$ This is important for the thinner patient with T1DM because weight loss would not be a priority.

\section{Dosage and administration}

Due to the risk of hypoglycemia, the manufacturer recommends that mealtime insulin should be reduced by $50 \%$ when starting pramlintide. The starting dose for T1DM is $15 \mathrm{mcg}$ subcutaneously before meals and titrated in $15 \mathrm{mcg}$ increments up to a max dose of $60 \mathrm{mcg}$. Waiting at least 3 days between dose titrations may minimize nausea. A dose reduction to $30 \mathrm{mcg}$ is recommended if nausea continues at the $60 \mathrm{mcg}$ dose. If patients are unable to tolerate $30 \mathrm{mcg}$ then pramlintide should be discontinued. Pramlintide is now available in two disposable multidose prefilled pen devices. The 60 pen-injector delivers doses of 15, 30, 45 and $60 \mathrm{mcg}$ and the 120 pen-injector delivers doses of 60 and $120 \mathrm{mcg}$.

Pramlintide should never be mixed with other insulins and should be administered subcutaneously in the abdomen or thigh at least 2 inches from insulin injection or pump sites. No dosing adjustments are required for renal impairment, but pramlintide has not been studied in patients on dialysis, with end-stage renal disease or hepatic impairment. Pramlintide is contraindicated in patients with hypoglycemia 
unawareness and gastroparesis. Pramlintide should be avoided for patients with poor compliance to current insulin regimen, poor compliance to self-monitoring BG, A1c $>9 \%$, recurrent severe hypoglycemia requiring assistance to treat in the past 6 months, or the use of medications to stimulate gastric motility. Pramlintide is not approved for use in pediatric patients. ${ }^{6}$

\section{Metformin}

\section{Mechanism of action and clinical effects}

Metformin, a biguanide, reduces hepatic glucose production, decreases intestinal glucose absorption and promotes peripheral glucose uptake and insulin sensitivity resulting in decreased fasting and postprandial glucose. As metformin does not modulate insulin, there is minimal hypoglycemic risk. ${ }^{8}$ Metformin has demonstrated long-term efficacy and safety, cost-effectiveness and potential reductions in cardiovascular (CV) events in T2DM, making it a first-line therapy for adult and pediatric patients. ${ }^{1}$ In T1DM, metformin is hypothesized to improve insulin resistance with the benefit of no additional hypoglycemic risk or weight gain and lower insulin doses. ${ }^{2,19}$

\section{Clinical evaluation}

Metformin has been evaluated in adult and pediatric patients with T1DM. Lund et al identified 100 patients with T1DM and A $1 \mathrm{c} \geq 8.5 \%$ in the previous year. If A $1 \mathrm{c}$ was $\geq 8 \%$ at the end of a 1-year, run-in period, they were randomized to receive metformin titrated to $1000 \mathrm{mg}$ twice daily or placebo in addition to insulin therapy for 12 months. Metformin-treated patients did not demonstrate a significant reduction in A1c compared to placebo $(0.13 \%, p=0.422)$; but A1c decreased significantly with placebo $(0.23 \%, 95 \% \mathrm{CI}[-0.45,-0.01])$. Between-group differences were significant in favor of metformin for TDID (-5.7 units, 95\% CI $[-8.6,-2.9], p<0.001)$ and body weight $(-1.74 \mathrm{~kg}, 95 \% \mathrm{CI}[-3.32,-0.17], p=0.030) .{ }^{20}$ Another trial evaluated metformin in 62 patients with T1DM on CSII and with an A1c $<9 \%$. Patients were randomized to metformin $850 \mathrm{mg}$ twice daily or placebo. Patients and/or investigators could adjust insulin doses based on self-monitored blood glucose (SMBG). Daily insulin requirements were significantly reduced with metformin compared to an increase in patients taking placebo ( $-4.3 \pm 9.9$ units and $1.7 \pm 8.3$ units, respectively; $p=0.0043)$. Basal insulin requirements were also significantly decreased with metformin $(-2.6 \pm 3.2$ units and 1.9 \pm 5.7 units, respectively; $p=0.023$ ). There was no difference in bolus insulin requirements or A1c. ${ }^{21}$

A retrospective study by Staels et al identified 242 patients with T1DM who had been recommended for adjunctive metformin and intensive insulin therapy. Patients were divided into two cohorts based on metformin duration 0-6 months (CTR) or $\geq 6$ months (MET) and compared to a reference cohort (REF) of patients with T1DM not offered metformin. At baseline, the REF cohort had a longer duration of diabetes and lower A1c than the metformin cohorts. Mean insulin dose was significantly lower in the MET cohort than the CTR cohort. Most patients (90\%) in the MET and CTR cohorts were overweight compared to $<40 \%$ in the REF cohort. After 10 years, there were no differences in A1c, insulin dose or BMI. This study suggests that metformin may not have long-term effects in T1DM but the study is limited by trial design. ${ }^{19}$

Two randomized trials evaluated metformin in overweight or obese patients with T1DM as adjunct to insulin therapy. Khan et al studied 15 overweight or obese patients with T1DM utilizing a randomized, crossover design. Following insulin optimization, patients were randomized to receive metformin $850 \mathrm{mg}$ daily titrated to $850 \mathrm{mg}$ three times daily or placebo for 16 weeks. Baseline BMI was $31.3 \pm 2.6 \mathrm{~kg} / \mathrm{m}^{2}$ and $\mathrm{A} 1 \mathrm{c}$ was $8.6 \% \pm 1.4 \%$. Metformin treatment resulted in significant reductions in A1c compared to placebo $(7.8 \pm 1.1$ versus $8.6 \% \pm 1.2 \% ; p<0.005)$. Metformin significantly reduced insulin doses from baseline $(50 \pm 13$ versus $60 \pm 14$ units; $p<0.05)$ and in comparison to placebo $(50 \pm 13$ versus $58 \pm 12$ units; $p<0.05)$. There was no significant difference in weight. Fasting plasma glucose (FPG) was also significantly reduced with metformin compared to placebo $(149.4 \pm 50.4$ versus $226.8 \pm 61.2 \mathrm{mg} / \mathrm{dL} ; p<0.001) .{ }^{22}$ Jacobsen et al evaluated 24 patients with T1DM and a mean BMI of 29.2 \pm 3.0 $\mathrm{kg} / \mathrm{m}^{2}$ after 6 months of metformin or placebo. Patients were randomized to metformin $500 \mathrm{mg}$ twice daily titrated to 1000 mg twice daily or placebo. No statistical difference was found in A1c or FPG between groups. At 6 months, TDID was significantly decreased in the metformin group compared to an increase in the placebo group $(-5.9 \pm 2.2$ versus $2.9 \pm 1.7 ; p=0.004)$. A significant decrease in weight was seen for metformin compared to placebo $(-3.9 \pm 1.5 \mathrm{~kg}, p=0.02){ }^{23}$

Petrie et al evaluated metformin's potential CV and glycemic effects over 3 years in 428 patients with T1DM and at least three prespecified CV risk factors. Patients were randomized to metformin titrated to $1000 \mathrm{mg}$ twice daily or placebo. There was no significant difference in the primary outcome and progression of average mean far-wall carotid artery intima-media thickness (cIMT) $(-0.005$ [-0.012, 0.002]; $p=0.1664)$. A1c was significantly reduced at 3 months but was not sustained $(-0.13 \%[-0.22,-0.04] ; p=0.0060)$. After 6 months, there was a slight reduction in insulin dose in metformin-treated 
patients $(-0.023$ units $/ \mathrm{kg},[-0.045,-0.0005] ; p=0.045)$ that diminished by 3 years. Weight $(-1.17 \mathrm{~kg}$, $[-1.66,-0.69]$; $p<0.0001)$ and low-density lipoprotein $(-2.3 \mathrm{mg} / \mathrm{dL},[-4.3$, $-0.5] ; p=0.0117$ ) were significantly reduced with metformin. Metformin significantly increased estimated glomerular filtration rate (eGFR) by $4.00 \mathrm{~mL} / \mathrm{min} / 1.73 \mathrm{~m}^{2}(p<0.0001)$. The tertiary outcome of averaged maximal far-wall cIMT demonstrated significance $(p=0.0093)$. As the trial did not meet power, conclusions are limited on these outcomes. Larger trials with clinical outcomes could provide additional information on $\mathrm{CV}$ risk in this population. ${ }^{24}$

Three randomized controlled trials evaluated metformin therapy in pediatric patients with T1DM. Hamilton et al investigated whether metformin would improve insulin sensitivity, glycemic control, insulin dose and BMI in 27 patients aged 12-17 years with T1DM, on insulin doses $>1$ unit $/ \mathrm{kg} /$ day and A1c $>8 \%$. Metformin was started at $500 \mathrm{mg}$ daily and titrated to 1000,1500 or $2000 \mathrm{mg}$ daily based on weight. At 3 months, no difference was found in insulin sensitivity $(p=0.26)$. A1c was $0.6 \%$ lower in the metformin group than the placebo group $(p<0.03)$. FPG significantly decreased with metformin but was the lowest at 2 months ( $-21.6 \pm 36$ versus $1.8 \pm 45 \mathrm{mg}$ / $\mathrm{dL} ; p=0.004)$. Insulin doses were also significantly lower in the metformin group $(-0.14 \pm 0.1$ versus $0.02 \pm 0.2$ units $/ \mathrm{kg} /$ day; $p<0.01$ ), which was attributed to lower doses of neutral protamine Hagedorn (NPH) insulin. There was a trend toward lower BMI in metformin-treated patients but it did not reach significance $(p<0.15) .{ }^{25}$ In another trial, 30 patients (aged 14-20 for girls, 16-20 years old for boys) with approximate mean A1c of $9.3 \%$ and insulin dose of 1.2 units $/ \mathrm{kg}$ were randomized to metformin or placebo for 3 months. Twenty-five patients were utilizing MDI and five CSII. Metformin was titrated to $1000 \mathrm{mg}$ twice daily. A1c significantly decreased from 9.6\% to $8.7 \%(95 \% \mathrm{CI}[-1.6,-0.1], p<0.05)$ in the metformin group and remained unchanged in the placebo group. No difference was found in insulin doses, BMI or lipids. A longer duration with sustained metabolic control may have demonstrated a difference in insulin dose because these patients were poorly controlled initially. Patients with decreased insulin sensitivity benefited greatest from metformin. ${ }^{26}$ Nadeau et al studied 74 pubertal adolescents aged 13-22 years with T1DM who were randomized to either metformin $500 \mathrm{mg}$ twice daily or placebo for 6 months. There were no significant differences in A1c. In the female subgroup, A1c was lower by $0.4 \%$ at 3 months but not statistically significant $(p=0.06)$. A trend toward lower A1c was seen in overweight or obese patients with metformin at 6 months. Metformin significantly decreased daily insulin dose in units and units $/ \mathrm{kg}(p<0.05, p=0.014$, respectively), whereas placebo increased insulin dose in units $(p=0.03)$ but was unchanged by units $/ \mathrm{kg}$. Men and women experienced a significantly greater decrease in daily insulin dose in units/ $\operatorname{kg}(p<0.04$ and $p<0.05$, respectively). Oddly, overweight and obese patients did not demonstrate a change in insulin dose but decreased units $/ \mathrm{kg}(1.23 \pm 0.24$ to $1.09 \pm 0.21 ; p=0.004)$. BMI z-score was significantly decreased within the metformin group $(0.77 \pm 0.63$ to $0.70 \pm 0.55 ; p=0.01)$. The lower metformin dose may have contributed to lack of benefit in some parameters but was utilized to avoid potential hypoglycemia. ${ }^{27}$

Two randomized controlled trials evaluated metformin added to insulin therapy in overweight or obese adolescent patients with T1DM. Libman et al included 140 patients aged 12-20 years with BMI $\geq 85$ th percentile for age and sex and A1c between $7.5 \%$ and $9.9 \%$ on at least 0.8 units $/ \mathrm{kg} /$ day of insulin. Metformin was titrated up to $1000 \mathrm{mg}$ twice daily. A1c decreased significantly at week 13 but was not sustained at week $26(0.2 \%$ in both groups; $p=0.92)$. Mean TDID per $\mathrm{kg}$ was lower in metformin-treated patients compared to placebo-treated patients $(-0.1[-0.2,-0.0] ; p<0.001)$. In addition, $23 \%$ in the metformin group demonstrated a $\geq 25 \%$ reduction in TDID $(p=0.003)$. BMI z-score decreased more in the metformin group compared to the placebo group $(-0.1$ $[-0.2,-0.1] ; p<0.001)$. BMI reductions of at least $10 \%$ from baseline occurred in $24 \%$ of the metformin group versus $7 \%$ of the placebo group $(p=0.01)$. More patients taking metformin had at least a $5 \%$ reduction in weight compared to placebo $(p=0.09) .{ }^{28}$ The second trial evaluated 28 patients with T1DM aged 10-20 years with BMI $>85 \%$ and A1c $>8 \%$ for 9 months who took metformin $1000 \mathrm{mg}$ daily or placebo in addition to current insulin therapy. A1c and FPG did not differ significantly between metformin and placebo $(p=0.903$ and $p=0.927$ ). The change in TDID between metformin and placebo was 0.31 units $/ \mathrm{kg}$ (1.42 versus 1.73 units $/ \mathrm{kg}$; $p=0.245$ ). Again, metformin was utilized at a lower dose to avoid severe hypoglycemia. This trial also followed an algorithm for insulin management, which may have affected results. In addition, this trial did not meet power, so results may have been significant with larger trial size. ${ }^{29}$

\section{Adverse effects}

\section{Gastrointestinal (Gl) effects}

GI effects, including diarrhea, nausea, vomiting and abdominal discomfort, are the most common AEs with metformin therapy. ${ }^{1}$ Several studies found low frequency or no difference in GI AEs. ${ }^{20-23,25,27}$ However, Libman et al reported 50 (70\%) GI events in metformin and $24(35 \%)$ events in placebo groups $(p<0.001) .{ }^{28}$ Treatment discontinuation occurred in 
$16 \%$ of patients on metformin in one trial compared to only $3 \%$ of patients on placebo. ${ }^{24}$ Another trial reported metformin discontinuation in only three patients receiving metformin. ${ }^{21}$ One trial reported a significant increase in metallic taste in the metformin group (metformin 7 , placebo $1 ; p=0.029$ ). ${ }^{20}$

\section{Lactic acidosis}

Lactic acidosis is uncommon when metformin is dosed appropriately in patients with renal dysfunction. Lactic acidosis was not reported in any of these trials. ${ }^{20-29}$

\section{BI2 deficiency}

Vitamin B12 deficiency is associated with long-term use of metformin. ${ }^{1}$ Petrie et al was the only trial to specifically address this potential long-term AE, and B12 deficiency was significantly increased in the metformin group (HR 2.76 $[1.28,5.95] ; p=0.0094) .{ }^{24}$

\section{Hypoglycemia}

When combined with intensive insulin therapy, hypoglycemia may occur if the insulin dose is not appropriately adjusted. The majority of trials found no difference in minor or major hypoglycemia. ${ }^{20-22,24,25,27,29}$ Jacobsen et al found a significant increase in biochemical hypoglycemia with metformin that was most evident in the first 8 weeks, correlating with insulin dose adjustments. No severe hypoglycemia occurred. ${ }^{23}$ Libman et al reported severe hypoglycemia in five patients treated with metformin versus none treated with placebo $(7 \%$ difference $[-9 \%, 23 \%] ; p=0.06)$. Most occurred in the first 6 weeks when insulin dose adjustments were still occurring. ${ }^{28}$ Nwosu et al found that nocturnal hypoglycemia was similar in the metformin and placebo groups. ${ }^{29}$

\section{Dosage and administration}

Metformin is an oral antihyperglycemic agent and should be started at a low dose with food to avoid GI effects. Extendedrelease (ER) metformin preparations may be preferred because of once-daily dosing and reduced GI effects. Glucophage $^{\circledR}$ is started at $500 \mathrm{mg}$ twice daily or $850 \mathrm{mg}$ daily with meals with a maximum daily dose of $2550 \mathrm{mg}$. Glucophage $\mathrm{XR}^{\circledR}$ is dosed at $500 \mathrm{mg}$ daily with a maximum daily dose of $2000 \mathrm{mg}$. The maximum pediatric dose of Glucophage is $2000 \mathrm{mg}$ daily. If Glucophage XR is not tolerated once daily, consider dividing the dose. If administered with insulin and FPG is $<120 \mathrm{mg} / \mathrm{dL}$, decrease insulin dose $10 \%-25 \%$ to avoid hypoglycemia. ${ }^{8}$ Metformin dosing recommendations in renal impairment may be based on eGFR instead of serum creatinine. Metformin is contraindicated in patients with an
eGFR $<30 \mathrm{~mL} / \mathrm{min} / 1.73 \mathrm{~m}^{2}$ and should not be initiated if eGFR is $30-45 \mathrm{~mL} / \mathrm{min} / 1.73 \mathrm{~m}^{2}$. Consider dose reductions if eGFR decreases below $45 \mathrm{~mL} / \mathrm{min} / 1.73 \mathrm{~m}^{2}{ }^{8}$ Metformin should not be given prior to certain procedures or administration of iodinated contrast dye. ${ }^{8}$

\section{Incretin mimetics}

\section{Mechanism of action and clinical effects}

GLP-1, an incretin hormone, regulates glucose levels and weight by increasing insulin secretion, decreasing glucagon secretion, slowing gastric emptying and promoting satiety; however, it is rapidly degraded by DPP- $4 .{ }^{30}$ Incretin mimetics, GLP-1 RAs and DPP-4 inhibitors, are recommended in T2DM because of low risk of hypoglycemia and potential for weight maintenance or loss. ${ }^{1,31}$ For patients with T1DM, incretin mimetics are of interest because of the potential to preserve beta-cell function, decrease glucagon and postprandial blood glucose (PBG) excursions and decrease total insulin doses with low risk of hypoglycemia. ${ }^{30,32}$ Sitagliptin and sitagliptin with lansoprazole in patients with newly diagnosed T1DM showed no change in c-peptide levels, A1c or body weight. ${ }^{33,34}$ Early studies with exenatide immediate release in T1DM also did not show improvement in beta-cell function as measured by c-peptide levels, but did suggest a benefit of reduced insulin doses, weight reductions, reduced PBG and improved insulin sensitivity with hypoglycemia rates similar to placebo. ${ }^{33,35,36}$ Further small, retrospective and observational studies of exenatide ER and liraglutide also showed A $1 \mathrm{c}$ reductions of $0.4 \%-0.9 \%$, weight reductions of $3.7 \%-5.1 \%$ and reductions in TDID of $13 \%-19 \%$ in adults with T1DM. ${ }^{37-39}$

\section{DPP-4 inhibitors}

DPP-4 inhibitors, specifically sitagliptin and vildagliptin, have been shown to decrease glucagon and increase GLP-1 levels after a meal without affecting counter-regulatory response during hypoglycemia. ${ }^{40-42}$ Some small studies have shown significant A1c reductions of $0.27 \%-0.32 \%$ after 4 weeks with sitagliptin ${ }^{40,43}$ but longer studies have shown no significant reductions. ${ }^{41,44}$ Changes in insulin requirements also vary from no change ${ }^{40,41}$ to minimal reductions of $0.051-$ 0.13 units $/ \mathrm{kg} /$ day with larger reductions seen in postprandial insulin use. ${ }^{43,44} \mathrm{~A}$ meta-analysis evaluating DPP-4 inhibitors in patients with T1DM showed no significant reductions in A1c and small reductions of 2.41 units/day in insulin dose. ${ }^{45}$ Given the insufficient evidence for A1c reduction, decrease in insulin dose and beta-cell preservation, the clinical utility of DPP-4 inhibitors is limited at this time. 


\section{GLP-I RAs}

\section{Clinical evaluation}

Clinical trials evaluating GLP-1 RAs are summarized in Table 2. Three, randomized controlled trials evaluated the use of liraglutide in adults with T1DM. The first included 30 patients, 10 patients with positive c-peptide and 20 with negative c-peptide. C-peptide-positive patients received liraglutide $1.2 \mathrm{mg}$ daily plus insulin and c-peptide-negative patients were randomized to receive insulin with or without liraglutide 1.2 $\mathrm{mg}$ daily for 4 weeks. At trial initiation, rapid-acting insulin dose was reduced by $50 \%$ and long-acting insulin by $0 \%-20 \%$ based on FPG. Although A1c decreased significantly in groups receiving liraglutide $(-0.26 \%$ to $-0.47 \%)$, there was no significant difference compared to insulin alone $(-0.18 \%)$. Insulin dose did decrease significantly by 0.194 units $/ \mathrm{kg} /$ day in c-peptide-positive patients and 0.13 units $/ \mathrm{kg} /$ day in c-peptide-negative patients receiving liraglutide compared to those receiving insulin alone $(+0.017 \mathrm{units} / \mathrm{kg} /$ day $) .{ }^{46} \mathrm{The}$ dose used in this study was not the maximum dose of liraglutide and the study size and duration were limited, which may have not shown the full benefit of liraglutide. Kuhadiya et al randomized 72 patients with T1DM to receive liraglutide $0.6,1.2$ or $1.8 \mathrm{mg}$ daily or placebo added to insulin therapy for 12 weeks. If baseline A $1 \mathrm{c}$ was $7 \%-7.5 \%$ or $\leq 7 \%$, insulin dose was reduced by $10 \%$ and $25 \%$, respectively. Liraglu- tide 1.2 and $1.8 \mathrm{mg}$ significantly reduced mean weekly BG $(-9.9 \mathrm{mg} / \mathrm{dL}$ in both groups) compared to liraglutide $0.6 \mathrm{mg}$ $(-0.18 \mathrm{mg} / \mathrm{dL})$ and placebo $(+0.72 \mathrm{mg} / \mathrm{dL})$. A1c decreased in all groups but only decreased significantly with liraglutide $1.2 \mathrm{mg}$ when compared to placebo $(-0.78 \%$ versus $-0.3 \%)$. TDID decreased with liraglutide 1.2 and $1.8 \mathrm{mg}$ by 12.1 and 10 units/day, respectively, compared to placebo (-1.9 units, $p<0.001)$. Almost $90 \%$ of patients receiving liraglutide lost weight with patients receiving 1.2 or $1.8 \mathrm{mg}$ losing a mean $5 \mathrm{~kg}$ $(p<0.001) .{ }^{47}$ It is unusual that A1c reductions did not occur in a dose-dependent manner. Another 12-week study evaluating only liraglutide $1.2 \mathrm{mg}$ daily compared to placebo included 40 adults with T1DM. Basal and bolus insulin doses were reduced by $10 \%$ and $25 \%$, respectively. After 12 weeks, A1c was reduced by $0.6 \%$ with liraglutide and $0.5 \%$ with placebo ( $p=0.62$ ); however, all changes in A1c and BG were similar between the two groups. Bolus insulin doses decreased significantly with liraglutide by 4 units/day compared to no change in the placebo group ( $p=0.02)$; however, basal insulin doses did not change significantly in either group. Body weight decreased by $3.1 \mathrm{~kg}$ with liraglutide and increased by $1.1 \mathrm{~kg}$ with placebo $(p<0.0001) .^{48}$ Two large, longer-term studies, ADJUNCT ONE and TWO, aimed to determine the effects of liraglutide $0.6,1.2$ and $1.8 \mathrm{mg}$ daily compared to placebo in adults with T1DM on glycemic control, insulin dose and

Table 2 Summary of randomized, controlled clinical trials with GLP-I RAs in TIDM

\begin{tabular}{|c|c|c|c|c|c|c|c|}
\hline Study & $\begin{array}{l}\text { Number } \\
\text { of } \\
\text { patient }\end{array}$ & $\begin{array}{l}\text { Study } \\
\text { duration, } \\
\text { weeks }\end{array}$ & \begin{tabular}{|l|} 
Mean \\
duration of \\
diabetes, \\
years
\end{tabular} & Treatment groups & $\begin{array}{l}\text { Change in } \\
\text { Alc (\%) }\end{array}$ & $\begin{array}{l}\text { Change in } \\
\text { insulin dose }\end{array}$ & $\begin{array}{l}\text { Change in } \\
\text { body } \\
\text { weight (kg) }\end{array}$ \\
\hline $\begin{array}{l}\text { Kielgast et al, }{ }^{46} \\
2011\end{array}$ & 39 & 4 & $\begin{array}{l}3.7 \\
17.3 \\
23.1\end{array}$ & $\begin{array}{l}\text { C-peptide pos + liraglutide } 1.2 \mathrm{mg} \text { daily } \\
\text { C-peptide neg + liraglutide } 1.2 \mathrm{mg} \text { daily } \\
\text { C-peptide neg + insulin alone }\end{array}$ & $\begin{array}{l}-0.26 \\
-0.47 \\
-0.18\end{array}$ & $\begin{array}{l}-0.194 \text { units } / \mathrm{kg} \\
-0.13 \text { units } / \mathrm{kg} \\
+0.017 \text { units } / \mathrm{kg}\end{array}$ & $\begin{array}{l}-2.3 \\
-2.3 \\
+0.2\end{array}$ \\
\hline $\begin{array}{l}\text { Frandsen et al, }{ }^{48} \\
2015\end{array}$ & 40 & 12 & $\begin{array}{l}18.3 \\
19.5\end{array}$ & $\begin{array}{l}\text { Liraglutide } 1.2 \mathrm{mg} \text { daily } \\
\text { Placebo }\end{array}$ & $\begin{array}{l}-0.6 \\
-0.5\end{array}$ & NR & $\begin{array}{l}-3.1 \\
+1.1\end{array}$ \\
\hline $\begin{array}{l}\text { Kuhadiya et al, }{ }^{47} \\
2016\end{array}$ & 72 & 12 & $\begin{array}{l}30 \\
25 \\
21 \\
20 \\
\end{array}$ & \begin{tabular}{|l} 
Placebo \\
Liraglutide $0.6 \mathrm{mg}$ daily \\
Liraglutide $1.2 \mathrm{mg}$ daily \\
Liraglutide $1.8 \mathrm{mg}$ daily
\end{tabular} & $\begin{array}{l}-0.3 \\
-0.26 \\
-0.78 \\
-0.42 \\
\end{array}$ & $\begin{array}{l}-1.9 \text { units } \\
-2.8 \text { units } \\
-12.1 \text { units } \\
-10.0 \text { units } \\
\end{array}$ & $\begin{array}{l}0 \\
-3.0 \\
-5.0 \\
-5.0 \\
\end{array}$ \\
\hline $\begin{array}{l}\text { Dejgaard et al, }{ }^{52} \\
2016\end{array}$ & 100 & 24 & $\begin{array}{l}20 \\
25\end{array}$ & $\begin{array}{l}\text { Liraglutide } 1.8 \mathrm{mg} \text { daily } \\
\text { Placebo }\end{array}$ & $\begin{array}{l}-0.5 \\
-0.3\end{array}$ & $\begin{array}{l}+4.1 \text { units } \\
+13.4 \text { units }\end{array}$ & $\begin{array}{l}-5.9 \\
+0.2\end{array}$ \\
\hline $\begin{array}{l}\text { Mathieu et al, }{ }^{49} \\
2016\end{array}$ & 1398 & 52 & $\begin{array}{l}20.9 \\
21.6 \\
21.5 \\
21.6\end{array}$ & $\begin{array}{l}\text { Liraglutide } 0.6 \mathrm{mg} \text { daily } \\
\text { Liraglutide } 1.2 \mathrm{mg} \text { daily } \\
\text { Liraglutide } 1.8 \mathrm{mg} \text { daily } \\
\text { Placebo }\end{array}$ & $\begin{array}{l}-0.43 \\
-0.49 \\
-0.54 \\
-0.34\end{array}$ & $\begin{array}{l}+4 \% \\
-2 \% \\
-5 \% \\
+4 \%\end{array}$ & $\begin{array}{l}-1.3 \\
-2.7 \\
-4.0 \\
+0.9\end{array}$ \\
\hline $\begin{array}{l}\text { Ahren et al, }{ }^{50} \\
2016\end{array}$ & 835 & 26 & $\begin{array}{l}21 \\
21.1 \\
21.4 \\
20.7\end{array}$ & $\begin{array}{l}\text { Liraglutide } 0.6 \mathrm{mg} \text { daily } \\
\text { Liraglutide } 1.2 \mathrm{mg} \text { daily } \\
\text { Liraglutide } 1.8 \mathrm{mg} \text { daily } \\
\text { Placebo }\end{array}$ & $\begin{array}{l}-0.24 \\
-0.23 \\
-0.35 \\
+0.01\end{array}$ & $\begin{array}{l}\text { NR } \\
\text { NR } \\
\text { NR } \\
\text { NR }\end{array}$ & $\begin{array}{l}-2.5 \\
-4.0 \\
-5.1 \\
-0.2\end{array}$ \\
\hline
\end{tabular}

Abbreviations: Alc, hemoglobin AIc; GLP-I RAs, glucagon-like peptide-I receptor agonists; neg, negative; NR, not reported; pos, positive; TIDM, type I diabetes mellitus. 
weight. ${ }^{49,50}$ ADJUNCT ONE included 1398 patients followed over 1 year and used a treat-to-target approach. ${ }^{49}$ ADJUNCT TWO included 835 patients followed over 26 weeks and implemented an insulin dose cap for study duration. ${ }^{50}$ In both studies, insulin dose was decreased by $25 \%$ upon liraglutide initiation with additional $10 \%$ decreases with dose titrations. ${ }^{49,50}$ ADJUNCT ONE showed significant decreases in A1c with liraglutide 1.2 and $1.8 \mathrm{mg}$ compared to placebo $(-0.49,-0.54$ versus $-0.34 \%$, respectively) despite the treatto-target approach. Total insulin doses, primarily driven by changes in postprandial insulin, decreased significantly with liraglutide 1.2 and 1.8 by $2 \%$ and $5 \%$, respectively, compared to a $4 \%$ increase with placebo. However, units $/ \mathrm{kg}$ of insulin was similar to baseline in all groups. Liraglutide resulted in significant weight loss of $1.3-4 \mathrm{~kg}$ for all doses compared to placebo $(\mathrm{p}<0.0001) .{ }^{49}$ In ADJUNCT TWO, A1c decreased significantly with all doses of liraglutide $(-0.24 \%,-0.23 \%$ and $-0.35 \%$ for $0.6,1.2$ and $1.8 \mathrm{mg}$, respectively) compared to placebo $(+0.01 \%)$. Insulin doses decreased significantly with liraglutide, again driven primarily by reductions in prandial insulin. Weight decreased significantly by $2.5-5.1 \mathrm{~kg}$ with liraglutide compared to placebo $(-0.2 \mathrm{~kg} ; p<0.0001) .{ }^{50}$ In subgroup analyses, patients with positive c-peptide were associated with greater decreases in A1c. These studies showed potential for improved glycemic control and reductions in postprandial insulin dose and continued to show weight reduction, suggesting that liraglutide therapy may have greater benefit in overweight or obese patients.

Two studies evaluated liraglutide specifically in overweight or obese patients. One retrospective study analyzed data from 27 obese patients with T1DM receiving liraglutide titrated to $1.8 \mathrm{mg}$ daily in addition to insulin. Patients at baseline had a mean weight of $96.2 \mathrm{~kg}$ and BMI of $33.3 \mathrm{~kg} /$ $\mathrm{m}^{2}$. Liraglutide decreased mean BG by $21 \mathrm{mg} / \mathrm{dL}, \mathrm{A} 1 \mathrm{c}$ by $0.43 \%$ and body weight by $4.6 \mathrm{~kg}$ while reducing TDID by 13 units and daily bolus dose by 11 units. ${ }^{51}$ Dejgaard et al conducted a 24-week, randomized, placebo-controlled trial in 100 adults with T1DM, a BMI over $25 \mathrm{~kg} / \mathrm{m}^{2}$ and A1c over $8 \%$ while on insulin therapy. Liraglutide was started at $0.6 \mathrm{mg}$ daily and titrated weekly to $1.8 \mathrm{mg}$ daily. Basal and bolus insulin were reduced by $25 \%$ and $33 \%$, respectively, upon liraglutide initiation. Liraglutide showed significant reductions in A1c at 12 weeks compared to placebo $(-0.6$ versus $-0.2, p=0.007)$; however, this difference diminished by 24 weeks. Body weight was significantly reduced by 6.8 $\mathrm{kg}$ with liraglutide compared to placebo $(p=0.015)$. Total insulin and bolus insulin doses decreased significantly over the 24-week study (-11.2 and -5.8 units/day); however, when adjusted for weight, no significant changes were seen. ${ }^{52}$ The results of this study show that liraglutide provides a benefit of weight reduction and may reduce bolus insulin requirements but may not improve glycemic control.

One study has evaluated the use of GLP-1 RAs in pediatric patients. Raman et al evaluated the use of exenatide on PBG in eight patients aged 13-22 years. Subjects underwent a standardized meal challenge at baseline and after administration of 1.25 and $2.5 \mathrm{mcg}$ of exenatide. On days subjects received exenatide, the bolus insulin dose was reduced by $20 \%$. Area under the curve for postprandial glucose was significantly reduced with the administration of exenatide compared to baseline $(p<0.007) .{ }^{53}$ While the study shows that exenatide may be beneficial in this population, there is no long-term data regarding A1c, insulin dose requirements or safety.

Finally, GLP-1 RAs have been studied as adjunctive treatment to insulin delivered by a closed-loop system to evaluate their effect on PBG excursions. One study included 10 patients with T1DM, aged $18-30$ years and with an A1c $<8.5 \%$ on CSII. Subjects underwent three crossover periods in which they received closed-loop delivery with insulin, closed-loop delivery with insulin and pramlintide $30 \mathrm{mcg}$, and closed-loop delivery with insulin and exenatide $25 \mathrm{mcg}$ for 1 day, with data collected before and after lunch and dinner meals. Exenatide showed significantly lower percentage of time when BG was $>180 \mathrm{mg} / \mathrm{dL}$ compared to insulin alone or insulin with pramlintide. Insulin doses were not significantly different between groups. ${ }^{54}$ A second study evaluated liraglutide $1.8 \mathrm{mg}$ daily in 11 adults with T1DM with A1c $\leq 9.0 \%$ on CSII. Subjects completed a closed-loop trial with insulin, followed by 3-4 weeks of liraglutide therapy and another closed-loop trial with insulin plus liraglutide. Compared to closed-loop insulin alone, administration of liraglutide significantly reduced average glucose excursion after all meals and decreased insulin requirements at meals by $28 \% .{ }^{55}$ Despite advances in technology, postprandial glucose excursions persist in patients with T1DM. These studies suggest a possible role for GLP-1 RAs as adjunct therapy in closed-loop systems with insulin but further research is needed to further elucidate which patients would benefit from this treatment option.

\section{Adverse effects \\ Hypoglycemia}

In most studies in adults, liraglutide showed no increase in time spent in hypoglycemia when compared to insulin alone. ${ }^{46-48}$ The incidence of any hypoglycemia and severe hypoglycemia was similar between liraglutide and 
placebo. ${ }^{46-49}$ The ADJUNCT ONE trial found significantly higher rates of symptomatic hypoglycemia with liraglutide 1.2 and $1.8 \mathrm{mg}$ compared to placebo with estimated rate ratio (ERR) of 1.31 and 1.27, respectively. ${ }^{49}$ ADJUNCT TWO found significantly higher rates or symptomatic hypoglycemia with $1.2 \mathrm{mg}$ only (ERR 1.31). ${ }^{50}$ Neither study found significantly higher rates of severe hypoglycemia with liraglutide ${ }^{49,50}$ Of note, each study included $6 \%-7 \%$ of patients with a history of severe hypoglycemia or hypoglycemia unawareness. Dejgaard et al found that overweight patients receiving liraglutide reported fewer hypoglycemia events based on SMBG, than for placebo, but this difference was not seen during CGM. ${ }^{52}$ Rates of hypoglycemia when liraglutide was used in combination with a closed-loop system and insulin were similar to insulin alone..$^{55}$

\section{Gl-related events}

Similar to patients with T2DM, the most common AEs with GLP-1 RAs were GI in nature and included nausea (40\%-95\%), abdominal distension (26\%), appetite suppression (14\%-50\%), dyspepsia (22\%), diarrhea (15.8\%-20\%) and vomiting $(2 \%-14 \%)$. Nausea was transient and tended to resolve after the first week of treatment initiation or dose titration. $^{46-52,55}$

\section{Hyperglycemia with ketosis}

The ADJUNCT ONE and TWO studies found that while rates of hyperglycemia were similar, rates of hyperglycemia with ketosis were higher with liraglutide 1.8 when compared to placebo, with ERR of 2.22-3.96. Rates tended to be lower in c-peptide-positive patients. ${ }^{49,50}$ In ADJUNCT ONE, all but one adjudicated cases of diabetic ketoacidosis (DKA) were precipitated by a concomitant factor (illness, pump malfunction) and all occurred in c-peptide-negative patients. ${ }^{49} \mathrm{In}$ ADJUNCT TWO, ketosis occurred most commonly in the first 8 weeks, which may be associated with insulin dose titration. ${ }^{50}$

\section{Dosing and administration}

Exenatide and liraglutide are both approved for the treatment of T2DM with no current indication for T1DM. Both medications are recommended to be started at a low dose and titrated to maximum doses to reduce the risk of GI-related AEs. Exenatide is started at $5 \mathrm{mcg}$ twice daily and titrated to $10 \mathrm{mcg}$ twice daily after 1 month. Liraglutide is started at 0.6 $\mathrm{mg}$ daily and titrated weekly by $0.6 \mathrm{mg}$ to a max dose of 1.8 $\mathrm{mg}$ daily. Liraglutide is also approved for the management of obesity in which the maximum dose is $3.0 \mathrm{mg}$ daily. Both are available in pen devices and administered subcutaneously. . $^{56,57}$

\section{SGLT2 inhibitors}

\section{Mechanism of action and clinical effects}

SGLT2 inhibitors provide glucose lowering by inhibiting SGLT2 in the proximal renal tubules, thus blocking glucose reabsorption. ${ }^{1}$ Some investigational agents also have dual SGLT2 and SGLT1 inhibition. The added SGLT1 inhibition occurs in the proximal intestine to further reduce glucose reabsorption. ${ }^{58}$ This may stimulate the release of GLP1 and polypeptide tyrosine tyrosine, which impact appetite and glucose control. ${ }^{59}$ In T2DM, SGLT2 inhibitors are recommended for the potential to decrease A1c, blood pressure and weight with a low risk of hypoglycemia. ${ }^{1,31}$ Additionally, canagliflozin and empagliflozin have proven CV mortality benefit in certain populations. ${ }^{60,61}$ For patients with T1DM, SGLT2 inhibitors may offer a benefit because the glucoselowering effect is independent of pancreatic function and, in overweight and obese patients, may also contribute to weight loss. ${ }^{1,31}$

\section{Clinical evaluation}

SGLT2 inhibitors have limited data as adjunct to insulin therapy in patients with T1DM. Safety of dapagliflozin was studied in 62 patients in a dose-ranging, randomized, doubleblind, proof-of-concept trial. Patients received dapagliflozin $1,2.5,5$ or $10 \mathrm{mg}$, or placebo with no insulin dose reductions at baseline. Treatment was initiated for 7 days in an inpatient facility, followed by 7 days of outpatient treatment. Only one serious AE was reported but determined unrelated to study treatment. Hypoglycemia was experienced by $60 \%-92.3 \%$ of patients in each group. One patient experienced major hypoglycemia on dapagliflozin but it was attributed to nonadherence to insulin reductions. Exploratory efficacy endpoints showed no significant difference between placebo and dapagliflozin in mean glucose measurements; however, dapagliflozin 5 and $10 \mathrm{mg}$ showed overall trends toward greater reductions in FPG, daily average glucose, mean amplitude of glucose excursion and change in TDID. ${ }^{62}$

Canagliflozin was studied in 351 patients in a Phase II, randomized, double-blind trial. Insulin doses were reduced $20 \%$ if A $1 \mathrm{c}>8 \%$ and $10 \%$ if A $1 \mathrm{c}<8 \%$. After 18 weeks, the primary endpoint of $\mathrm{A} 1 \mathrm{c}$ reduction of $\geq 0.4 \%$ and no body weight increase was achieved by $36.9 \%, 41.4 \%$ and $14.5 \%$ of patients for canagliflozin 100 and $300 \mathrm{mg}$ and placebo, respectively ( $p<0.001$ for both comparisons). From a baseline A1c of $7.9 \%$, the change in A1c was $-0.27 \%$ and $-0.24 \%$ for canagliflozin 100 and $300 \mathrm{mg}$ compared to $+0.04 \%$ in the placebo group. Both doses of canagliflozin resulted in weight loss and decreased TDID compared to placebo. 
Similar to T2DM, AEs included volume-related AEs and genitourinary infections. Nearly all patients experienced hypoglycemia but $2.6 \%, 6.8 \%$ and $1.7 \%$ experienced severe hypoglycemia (canagliflozin 100 and $300 \mathrm{mg}$ and placebo, respectively). Despite exclusion of patients with recent DKA, ketone-related AEs were reported in 5.1\% and $9.4 \%$ of the canagliflozin 100 and $300 \mathrm{mg}$ groups, none were reported with placebo. DKA requiring hospitalization occurred in 12 patients but all were associated with a precipitating factor. Notably, five patients had a $B G<250 \mathrm{mg} / \mathrm{dL}$ at the time of hospitalization. ${ }^{63} \mathrm{~A}$ follow-up study determined no identifiable differences in baseline demographics predictive of DKA in people with T1DM taking canagliflozin. ${ }^{64}$

Empagliflozin $25 \mathrm{mg}$ was studied in 40 patients in an open-label, proof-of-concept trial. Basal and prandial insulin doses were reduced by $30 \%$ at baseline. After 8 weeks, the baseline A1c of $8 \% \pm 0.9 \%$ decreased to $7.6 \% \pm 0.9 \%$ $(p<0.0001)$ with greater reductions in those with baseline A1c $>8 \%$. Although carbohydrate intake increased, prandial insulin doses remained stable while basal insulin doses were reduced $(25.7 \pm 10.6$ units to $19.5 \pm 7.9$ units, $p<0.00001)$. Weight and waist circumference also significantly decreased ( $p<0.0001$ for both). Symptomatic hypoglycemia decreased from 0.12 to 0.04 episodes/patient/day from baseline to end of treatment ( $p=0.0004)$. Two patients experienced DKA although presenting BG values were 306 and $212 \mathrm{mg} / \mathrm{dL}$. There were precipitating factors but it is notable that their total insulin doses were reduced $70 \%$ and $50 \%$ shortly after trial initiation based on investigator instruction. ${ }^{65}$

EASE-1 evaluated empagliflozin in a randomized, placebo-controlled, Phase II study of 75 patients. Patients remained at an inpatient facility and insulin doses were adjusted for safety during the first 7 days of treatment. Then, patients were discharged and insulin could be freely adjusted. At day 28 , baseline A1c $8.24 \%$ was significantly reduced by $0.53 \%, 0.54 \%, 0.67 \%$ and $0.18 \%$ for empagliflozin 2.5 , 10 and $25 \mathrm{mg}$ and placebo, respectively $(p=0.01,0.008$ and $<0.001$ for $2.5,5$ and $10 \mathrm{mg}$ versus placebo). FPG and mean daily glucose were numerically lower in treatment groups versus placebo. During the fourth week of treatment, the weekly mean total recorded insulin dose decreased by 0.08 , $0.10,0.08$ and 0.01 units $/ \mathrm{kg}$ for empagliflozin 2.5, 10 and $25 \mathrm{mg}$ and placebo, respectively $(p=0.044,0.013$ and $<0.023$ for $2.5,5$ and $10 \mathrm{mg}$ versus placebo). While there were significant changes in weight, no significant differences were observed in systolic or diastolic blood pressure. Symptomatic hypoglycemia with plasma glucose $\geq 54$ to $\leq 70 \mathrm{mg} / \mathrm{dL}$, not requiring assistance, was observed in $2.4,3.1,3.4$ and 2.9 episodes per 30 days (empagliflozin 2.5, 10 and $25 \mathrm{mg}$ and placebo, respectively). Symptomatic hypoglycemia with plasma glucose $\leq 54 \mathrm{mg} / \mathrm{dL}$, not requiring assistance, was observed in $0.4,0.5,0.8$ and 1 episode per 30 days (empagliflozin 2.5, 10 and $25 \mathrm{mg}$ and placebo, respectively). One episode of hypoglycemia requiring assistance occurred in the placebo group. There were no reports of DKA. ${ }^{66}$

Sotagliflozin is a dual SGLT1 and SGLT2 inhibitor, not currently approved in the US, which has been studied in two trials. The first is a randomized, placebo-controlled, doubleblind study comparing sotagliflozin $400 \mathrm{mg}$ versus placebo in 33 patients. Initial insulin adjustments were based on a pilot, open-label evaluation of three patients, and were managed over 2 days in an inpatient setting. Sotagliflozin was associated with a $32 \%$ decrease in bolus insulin dose as compared to a $6.4 \%$ decrease with placebo $(p=0.0007)$ at day 28 . The difference between treatment and placebo was significant after all meals but reductions in bolus insulin dose trended down throughout the day after taking sotagliflozin before the first meal. Overall TDID was also reduced with sotagliflozin as compared to placebo ( $15.3 \%$ versus $0.7 \%$, respectively, $p=0.002$ ); however, differences in basal insulin doses were not significant. Glucose values measured by CGM showed that sotagliflozin was associated with lower mean daily glucose values versus placebo (148.8 mg/dL versus $170.3 \mathrm{mg} /$ $\mathrm{dL}, p=0.01)$. Patients on treatment also remained in target glucose ranges $(70-180 \mathrm{mg} / \mathrm{dL})$ more often $(p=0.003)$ with a small difference in time spent $<70 \mathrm{mg} / \mathrm{dL}$ (6.7\% versus $5.8 \%$, sotagliflozin and placebo, respectively; $p=0.8$ ). At day 29, A1c was reduced $0.55 \%$ versus $0.06 \%(p=0.02)$. There was no severe hypoglycemia but there were 304 hypoglycemic events reported in the sotagliflozin group $(n=16)$ and 354 events in the placebo group $(n=16)$. Overall hypoglycemia was slightly lower than baseline in both groups. Two patients in the sotagliflozin group experienced DKA but both were attributed to insulin infusion pumps and not drug related. Eight patients versus three patients experienced some GI disorder (sotagliflozin versus placebo, respectively), with mild nausea being more likely with sotagliflozin. Sotagliflozin was also associated with weight loss. ${ }^{59}$ The inTandem 3 trial evaluated sotagliflozin $400 \mathrm{mg}$ in a Phase III, randomized, double-blind, placebo-controlled study of 1402 patients. Bolus insulin was decreased $30 \%$ for the first meal after the first dose of drug. At week 24 , sotagliflozin showed a statistically significant benefit in the primary endpoint, achievement of A1c $<7 \%$ with no severe hypoglycemia or DKA $(28.6 \%$ versus $15.2 \%, p<0.001)$. The baseline A1c $8.2 \%$ was lowered $0.79 \%$ with treatment, as compared to $-0.33 \%$ with placebo $(p<0.01)$. This was 
achieved despite decreased TDID with sotagliflozin $(-6.8 \%$ versus $+2.9 \%, p<0.001)$. Overall hypoglycemia (BG $\leq 70 \mathrm{mg} /$ dL) was similar between groups; however, sotagliflozin was associated with more severe hypoglycemia (3\% versus $2.4 \%$ ). It was also associated with more DKA (3\% versus $0.6 \%)$, which in turn resulted in higher treatment discontinuation rates. Due to SGLT1 inhibition, diarrhea was more common with treatment. Sotagliflozin was also associated with greater weight loss and lower systolic blood pressure. ${ }^{67}$

\section{Adverse effects}

\section{Hypoglycemia}

Hypoglycemia was common in all studies, including among placebo groups. Some studies showed lower or similar rates of severe hypoglycemia when comparing SGLT2 inhibitors to placebo, ${ }^{59,66}$ while others showed increased risk with SGLT2 inhibitors. ${ }^{64,67}$ Two trials noted lower rates of hypoglycemia as compared to baseline..$^{59,65}$

\section{Diabetic ketoacidosis}

Although DKA was rare and usually precipitated by other factors, it was more common among patients taking an SGLT2 inhibitor. One study noted higher rates with patients using insulin pumps, so patients should closely monitor for potential pump failures. ${ }^{67}$ Two studies noted that BG in DKA was lower than expected, ${ }^{65,68}$ which aligns with other reports of euglycemic DKA. ${ }^{68,69}$ Patients should be educated and carefully monitored, as case reports indicate that DKA is more likely to occur in T1DM and overlooked because of the lack of hyperglycemia. ${ }^{68-70}$ If risk factors including acute illness, increased activity, decreased carbohydrate intake and reduced insulin doses are identified, medication may be withheld. ${ }^{68,70}$

\section{Genitourinary infections}

Genital mycotic infections and, to a lesser degree, urinary tract infections (UTIs) are known AEs with this class of drugs. Henry et al reported that $5.1 \%$ of patients experienced UTIs and $21.2 \%$ of women experienced genital mycotic infections when taking canagliflozin $300 \mathrm{mg} .{ }^{63}$ Garg et al reported that $6.4 \%$ of patients using sotagliflozin experienced genital mycotic infections. ${ }^{67}$ However, some studies found no difference versus placebo..$^{59,62,66}$

\section{Volume-related adverse events}

SGLT2 inhibitors are associated with hypotension and other volume-related AEs. Although most trials did not report these, canagliflozin was reported to result in volume-related AEs in $3.4 \%$ of patients, significantly more than placebo. ${ }^{63}$
Sotagliflozin was associated as well, although it was less common at $1.9 \%{ }^{67}$

\section{Dosing and administration}

Canagliflozin, dapagliflozin and empagliflozin are approved for the treatment of T2DM; however, no SGLT2 inhibitors are currently approved for use in T1DM. All three are recommended to be started at the lower dose and titrated. Currently available doses include canagliflozin 100 and $300 \mathrm{mg}$, dapagliflozin 5 and $10 \mathrm{mg}$, and empagliflozin 10 and $25 \mathrm{mg}$. Based on the available evidence, insulin reductions up to $30 \%$ may be necessary but risk of DKA should be considered. ${ }^{62,65}$

\section{Combination therapy}

Studies evaluating the addition of multiple adjunctive therapies are rare. One study evaluated the addition of dapagliflozin to insulin and liraglutide in 26 patients with T1DM over 12 weeks. The addition of dapagliflozin resulted in a $0.66 \%$ reduction in A1c compared to a $0.1 \%$ reduction with placebo $(p<0.01)$ as well as a $1.9 \mathrm{~kg}$ weight loss. Rates of hypoglycemia and insulin doses remained similar in both groups. However, glucagon levels and urinary ketone levels increased significantly with dapagliflozin. Two patients experienced DKA with dapagliflozin use. ${ }^{71}$ Further studies are needed to elucidate the efficacy and safety of combination adjunctive therapies and which patients may benefit.

\section{Therapeutic considerations and place in therapy}

Pramlintide, metformin, GLP-1 RAs and SGLT2 inhibitors may play a role in the management of T1DM in select patients not well controlled on insulin therapy. In general, the benefits of these agents include weight loss, decreased insulin dose and minimal risk of hypoglycemia. Adjunctive therapies should be considered for patients not reaching A1c goals on intensive insulin therapy, especially if insulin doses are limited by AEs. Depending on the timing of hyperglycemia, some agents may be more effective. Pramlintide and GLP-1 RAs may have greater reductions in PBG while metformin may have a larger effect on FBG. Given the weight loss seen with each medication class, overweight and obese patients may see more benefit with adjunctive therapy than patients with normal weight. While most adjunctive options have low risks of hypoglycemia, it remains a concern, especially with pramlintide and liraglutide. Insulin doses should be closely monitored and adjusted to prevent hypoglycemia if adjunctive therapy is initiated. Patients should be motivated to achieve good glycemic control and closely monitor BG and should 
have a good understanding of insulin management. Pramlintide and liraglutide should be used with extreme caution in patients with a history of severe hypoglycemia or hypoglycemia unawareness. Some populations may benefit more from certain agents. Metformin and liraglutide have been studied in adolescent patients, so preference should be given to these agents in this age group. Metformin and SGLT2 inhibitors must be dose-adjusted or discontinued based on renal function, so these agents should be monitored closely or avoided in patients with renal impairment. There is not sufficient data to support the use of multiple adjunct therapies in combination.

Practical considerations that may influence the choice of adjunctive therapy include route of administration, cost and AEs. Pramlintide and GLP-1 RAs require subcutaneous administration, which will increase the number of daily injections and may impact compliance. Metformin and SGLT2 inhibitors provide an oral option, which may be preferred for some patients. Metformin provides the most affordable option as it is generically available. The other options confer significant cost in addition to the cost of insulin therapy. GIrelated events, specifically nausea and diarrhea, are the most common AEs for pramlintide and GLP-1 RAs, and metformin, respectively. Nausea with pramlintide and GLP-1 RAs seems to be dose-dependent, transient and is reduced with slow titration schedules. Diarrhea may be reduced with slow titration or use of ER formulations of metformin. SGLT2 inhibitors may be associated with increased risk of genitourinary infections or AEs related to volume depletion. Caution should be used in patients with a history of UTIs or mycotic infections or patients taking concurrent antihypertensive agents. SGLT2 inhibitors have been associated with increased risk of DKA and liraglutide was associated with hyperglycemia with ketosis. Caution should be used with these agents in patients at high risk of DKA or those with acute illness.

Continued research for adjunct therapies in T1DM may provide additional options in the future that address the limitations of current therapies. One class in development is glucagon receptor antagonists. In a recent proof-of-concept trial, one of these agents showed potential for improved glycemic control and decreased insulin doses in type 1 diabetes. $^{72}$ However, potential side effects of other developmental agents in this class include weight gain, increased cholesterol, and alpha-cell hyperplasia. Further research is needed to determine the clinical utility of this class. ${ }^{73}$

\section{Summary}

Adjunctive therapies including pramlintide, metformin, GLP-1 RAs and SGLT2 inhibitors may help patients with
T1DM reach glycemic goals while reducing insulin doses, promoting weight loss and limiting hypoglycemia. Patients not reaching A1c goals with insulin therapy and those who could benefit from weight loss are most likely to benefit from adjunctive therapy. Patient-specific characteristics as well as AEs should be considered when selecting appropriate therapy.

\section{Disclosure}

Dr. Kira Harris is on the speakers' bureau for Janssen Pharmaceuticals, Inc. The other authors report no conflicts of interest in this work.

\section{References}

1. American Diabetes Association. Standards of medical care in diabetes-2017. Diabetes Care. 2017;40:S1-S135.

2. Frandsen CS, Dejgaard TF, Madsbad S. Non-insulin drugs to treat hyperglycaemia in type 1 diabetes mellitus. Lancet Diabetes Endocrinol. 2016;4(9):766-780.

3. The Diabetes Control and Complications Trial Research Group, Nathan $\mathrm{DM}$, Genuth S, et al. The effect of intensive treatment of diabetes on the development and progression of long-term complications in insulindependent diabetes mellitus. N Engl J Med. 1993;329(14):977-986.

4. Diabetes Control and Complications Trial (DCCT)/Epidemiology of Diabetes Interventions and Complications (EDIC) Study Research Group. Intensive diabetes treatment and cardiovascular outcomes in type 1 diabetes: the DCCT/EDIC study 30-year follow-up. Diabetes Care. 2016;39(5):686-693.

5. Livingstone R, Boyle JG, Petrie JR; REMOVAL Study Team. A new perspective on metformin therapy in type 1 diabetes. Diabetologia. 2017;60(9):1594-1600.

6. AstraZeneca Pharmaceuticals, Symlin (pramlintide acetate) injection [package insert]. Wilmington, DE, USA: 2016.

7. Miller KM, Foster NC, Beck RW, et al. Current state of type 1 diabetes treatment in the US: updated data from the T1D exchange clinic registry Diabetes Care. 2015;38(6):971-978.

8. Bristol-Myers Squibb, Glucophage (metformin hydrochloride) [package insert]. Princeton, NJ, USA: 2017.

9. Whitehouse F, Kruger DF, Fineman M, et al. A randomized study and open-label extension evaluating the long-term efficacy of pramlintide as an adjunct to insulin therapy in type 1 diabetes. Diabetes Care. 2002;25(4): 724-730.

10. Ratner RE, Dickey R, Fineman M, et al. Amylin replacement with pramlintide as an adjunct to insulin therapy improved long-term glycemic and weight control in type 1 diabetes mellitus: a 1-year, randomized controlled trial. Diabet Med. 2004;21(11):1204-1212.

11. Ratner R, Whitehouse F, Fineman MS, et al. Adjunctive therapy with pramlintide lowers $\mathrm{HbA} 1 \mathrm{c}$ without concomitant weight gain in patients with type 1 diabetes approaching glycemic targets. Exp Clin Endocrinol Diabetes. 2005;113(4):199-204.

12. Edelman S, Garg S, Frias J, et al. A double-blind, placebo-controlled trial assessing pramlintide treatment in the setting of intensive insulin therapy in type 1 diabetes. Diabetes Care. 2006;29(10):2189-2195.

13. Marrero DG, Crean J, Zhang B, et al. Effect of adjunctive pramlintide treatment on treatment satisfaction in patients with type 1 diabetes. Diabetes Care. 2007;30(2):210-216.

14. Levetan C, Want LL, Weyer C, et al. Impact of pramlintide on glucose fluctuations and postprandial glucose, glucagon and triglyceride excursions among patients with type 1 diabetes intensively treated with insulin pumps. Diabetes Care. 2003;26(1):1-8.

15. Kruger DF, Aronoff SL, Edelman SV. Through the looking glass: current and future perspective on the role of hormonal interplay in glucose homeostasis. Diabetes Educ. 2007;33(Suppl 2):32S-46S. 
16. Hieronymus L, Griffin S. Role of amylin in type 1 and type 2 diabetes. Diabetes Educ. 2015;41(Suppl 1):47S-56S.

17. Purnell JQ, Hokanson JE, Marcovina SM, Steffes MW, Cleary PA, Brunzell JD. Effect of excessive weight gain with intensive therapy of type 1 diabetes on lipid levels and blood pressure. JAMA. 1998;280(2):140-146.

18. Ryan G, Briscoe TA, Jobe L. Review of pramlintide as adjunctive therapy in treatment of type and type 2 diabetes. Drug Des Devel Ther. 2008;2:203-214.

19. Staels F, Moyson C, Mathieu C. Metformin as add-on to intensive insulin therapy in type 1 diabetes mellitus. Diabetes Obes Metab. 2017;19(10):1463-1467.

20. Lund SS, Tarnow L, Astrup AS, et al. Effect of metformin treatment in patients with type-1 diabetes and persistent inadequate glycaemic control. A randomized study. PLoS One. 2008;3(10):e3363.

21. Meyer L, Bohme P, Delbachian I, et al. The benefits of metformin therapy during continuous subcutaneous insulin infusion treatment of type 1 diabetic patients. Diabetes Care. 2002;25(12):2153-2158.

22. Khan AS, McLoughney CR, Ahmed AB. The effect of metformin on blood glucose control in overweight patients with type 1 diabetes. Diabet Med. 2006;23(10):1079-1084.

23. Jacobsen IB, Henriksen JE, Beck-Nielsen H. The effect of metformin in overweight patients with type 1 diabetes and poor metabolic control. Basic Clin Pharmacol Toxicol. 2009;105(3):145-149.

24. Petrie JR, Chaturvedi N, Ford I, et al. Cardiovascular and metabolic effects of metformin in patients with type 1 diabetes (REMOVAL): a double-blind, randomized, placebo-controlled trial. 2017;5(8):597-609.

25. Hamilton J, Cummings E, Zdravkovic V, Finegood D, Daneman D. Metformin as an adjunct therapy in adolescents with type 1 diabetes and insulin resistance. Diabetes Care. 2003;26(1):138-143.

26. Särnblad S, Kroon M, Aman J. Metformin as additional therapy in adolescents with poorly controlled type 1 diabetes: randomised placebocontrolled trial with aspects on insulin sensitivity. Eur J Endocrinol. 2003;149(4):323-329.

27. Nadeau KJ, Chow K, Alam S, et al. Effects of low dose metformin in adolescents with type 1 diabetes mellitus: a randomized, double-blinded placebo-controlled study. Pediatr Diabetes. 2015;16(3):196-203.

28. Libman IM, Miller KM, DiMeglio LA, et al; T1D Exchange Clinic Network Metformin RCT Study Group. Effect of metformin added to insulin on glycemic control among overweight/obese adolescents with type 1 diabetes a randomized clinical trial. JAMA. 2015;314(21): 2241-2250.

29. Nwosu BU, Maranda L, Cullen K, et al. A randomized, double-blind, placebo-controlled trial of adjunctive metformin therapy in overweight/ obese youth with type 1 diabetes. PLoS One. 2015;10(9):e0137525.

30. Kielgast U, Holst JJ, Madsbad S. Treatment of type 1 diabetic patients with glucagon-like peptide (GLP-1) and GLP-1R agonists. Curr Diabetes Rev. 2009;5(4):266-275.

31. Garber AJ, Abrahamson MJ, Barzilay JI, et al. Consensus statement by the American association of clinical endocrinologists and american college of endocrinology on the comprehensive type 2 diabetes management algorithm - 2017 executive summary. Endocr Pract. 2017;23(2):207-238.

32. Unger J. Rationale use of GLP-1 receptor agonists in patients with type 1 diabetes. Curr Diab Rep. 2013;13(5):663-668.

33. Hari Kumar KV, Shaikh A, Prusty P. Addition of exenatide or sitagliptin to insulin in new onset type 1 diabetes: a randomized, open label study. Diabetes Res Clin Pract. 2013;100(2):e55-e58.

34. Griffin KJ, Thompson PA, Gottschalk M, Kyllo JH, Rabinovitch A. Combination therapy with sitagliptin and lansoprazole in patients with recent-onset type 1 diabets (REPAIR-T1D): 12 month results of a multicentre, randomised, placebo-controlled, phase 2 trial. Lancet Diabetes Endocrinol. 2014;2(9):710-718.

35. Rother KI, Spain LM, Wesley RA, et al. Effects of exenatide alone and in combination with daclizumab on $\beta$-cell function in long-standing type 1 diabetes. Diabetes Care. 2009;32(12):2251-2257.
36. Sarkar G, Alattar M, Brown R, et al. Exenatide treatment for 6 months improves insulin sensitivity in adults with type 1 diabetes. Diabetes Care. 2014;37(3):666-670.

37. Varanasi A, Bellini N, Rawal D, et al. Liraglutide as additional treatment for type 1 diabetes. Eur J Endocrinol. 2011;165(1):77-84.

38. Harrison LB, Mora PF, Clark GO, Lingvay I. Type 1 diabetes treatment beyond insulin: role of GLP-1 analogs. J Investig Med. 2013;61(1):40-44.

39. Traina AN, Lull ME, Hui AC, Zahorian TM, Lyons-Patterson J. Onceweekly exenatide as adjunct treatment of type 1 diabetes mellitus in patient receiving continuous subcutaneous insulin infusion therapy. Can J Diabetes. 2014;38(4):269-272.

40. Farngren J, Persson M, Schweizer A, Foley JE, Ahren B. Vildagliptin reduces glucagon during hyperglycemia and sustains glucagon counterregulation during hypoglycemia in type 1 diabetes. J Clin Endocrinol Metab. 2012;97(10):3799-3806.

41. Garg SK, Moser EG, Bode BW, et al. Effect of sitagliptin on postprandial glucagon and GLP-1 levels in patients with type 1 diabetes: investigatorinitiated, double-blind, randomized, placebo-controlled trial. Endocr Pract. 2013;19(1):19-28.

42. Schopman JE, Hoekstra JB, Frier BM, et al. Effects of sitagliptin on counter-regulatory and incretin hormones during acute hypoglycaemia in patient with type 1 diabetes: a randomized double-blind placebo-controlled crossover study. Diabetes Obes Metab. 2015;17(6): 546-553.

43. Ellis SL, Moser EG, Snell-Gerbeon JK, Rodionova AS, Hazenfield RM, Garg SK. Effect of sitagliptin on glucose control in adult patients with type 1 diabetes: a pilot, double-blind, randomized, crossover trial. Diabet Med. 2011;28(10):1176-1181.

44. Giampietro O, Giampietro C, Bartola LD, Masoni MC, Matteucci E. Sitagliptin as add-on therapy in insulin-deficiency: biomarkers of therapeutic efficacy respond differently in type 1 and type 2 diabetes. Drug Des Devel Ther. 2013;7:99-104.

45. Guo H, Fang C, Huang Y, Pei Y, Chen L, Hu J. The efficacy and safety of DPP4 inhibitors in patients with type 1 diabetes: a systematic review and meta-analysis. Diabetes Res Clin Pract. 2016;121:184-191.

46. Kielgast U, Krarup T, Holst JJ, Madsbad S. Four weeks of treatment with liraglutide reduces insulin dose without loss of glycemic control in type 1 diabetic patients with and without residual beta-cell function. Diabetes Care. 2011;34(7):1463-1468.

47. Kuhadiya ND, Dhindsa S, Ghanim H, et al. Addition of liraglutide to insulin in patients with type 1 diabetes: a randomized placebo-controlled clinical trial of 12 weeks. Diabetes Care. 2016;39(6):1027-1035.

48. Frandsen CS, Dejgaard TF, Holst JJ, Andersen HU, Thorsteinsson B, Madsbad S. Twelve-week treatment with liraglutide as add-on to insulin in normal-weight patients with poorly controlled type 1 diabetes: a randomized, placebo-controlled, double-blind parallel study. Diabetes Care. 2015;38(12):2250-2257.

49. Mathieu C, Zinman B, Hemmingsson JU, et al. Efficacy and safety of liraglutide added to insulin treatment in type 1 diabetes: the ADJUNCT ONE treat-to-target randomized trial. Diabetes Care. 2016;39(10): $1702-1710$.

50. Ahren B, Hirsch IB, Pieber TR, et al. Efficacy and safety of liraglutide added to capped insulin treatment in subjects with type 1 diabetes: the ADJUNCT TWO randomized trial. Diabetes Care. 2016;39(10):1693-1701.

51. Kuhadiya ND, Malik R, Bellini NJ, et al. Liraglutide as additional treatment to insulin in obese patients with type 1 diabetes mellitus. Endocr Pract. 2013;19(6):963-967.

52. Dejgaard TF, Frandsen CS, Hansen TS, et al. Efficacy and safety of liraglutide for overweight adult patients with type 1 diabetes and insufficient glycaemic control (Lira-1): a randomized, double-blind, placebocontrolled trial. Lancet Diabetes Endocrinol. 2016;4(3):221-232.

53. Raman VS, Mason KJ, Rodriguez LM, et al. The role of adjunctive exenatide therapy in pediatric type 1 diabetes. Diabetes Care. 2010;33(6):1294-1296. 
54. Renukuntla VS, Ramchandani N, Trast J, Cantwell M, Heptulla RA. Role of glucagon-like peptide-1 anaglogue versus amylin as adjuvant therapy in type 1 diabetes in a closed loop setting with ePID algorithm. J Diabetes Sci Technol. 2014;8(5):1011-1017.

55. Sherr JL, Patel NS, Michaud CI, et al. Mitigating meal-related glycemic excursions in an insulin-sparing manner during closed-loop insulin delivery: the beneficial effects of adjunctive pramlintide and liraglutide. Diabets Care. 2016;39(7):1127-1134.

56. Amylin Pharmaceuticals, Inc, Byetta (exenatide) [package insert]. San Diego, CA, USA: 2009.

57. Novo Nordisk A/S, Inc, Victoza (liraglutide) [package insert]. Bagsvaerd, Denmark: 2017.

58. Bode BW, Garg SK. The emerging role of adjunctive noninsulin antihyperglycemic therapy in the management of type 1 diabetes. Endocr Pract. 2016;22(2):220-230.

59. Sands AT, Zambrowicz BP, Rosenstock J, et al. Sotagliflozin, a dual SGLT1 and SGLT2 inhibitor, as adjunct therapy to insulin in type 1 diabetes. Diabetes Care. 2015;38(7):1181-1188.

60. Neal B, Perkovic V, Mahaffey KW, et al; CANVAS Program Collaborative Group. Canagliflozin and cardiovascular and renal events in type 2 diabetes. $N$ Engl J Med. 2017;377(7):644-657.

61. Zinman B, Wanner C, Lachin JM, et al. Empagliflozin, cardiovascular outcomes, and mortality in type 2 diabetes. $N$ Engl J Med. 2015;373(22):2117-2128.

62. Henry RR, Rosenstock J, Edelman S, et al. Exploring the potential of the SGLT2 inhibitor dapagliflozin in type 1 diabetes: a randomized, double-blind, placebo-controlled pilot study. Diabetes Care. 2015;38(3):412-419.

63. Henry RR, Thakkar P, Tong C, Polidori D, Alba M. Efficacy and safety of canagliflozin, a sodium-glucose cotransporter 2 inhibitor, as add-on to insulin in patients with type 1 diabetes. Diabetes Care. 2015;38(12):2258-2265.
64. Peters AL, Henry RR, Thakkar P, Tong C, Alba M. Diabetic ketoacidosis with canagliflozin, a sodium-glucose cotransporter 2 inhibitor, in patients with type 1 diabetes. Diabetes Care. 2016;39(4):532-538.

65. Perkins BA, Cherney DZ, Partridge H, et al. Sodium-glucose cotransporter 2 inhibition and glycemic control in type 1 diabetes: results of an 8-week open-label proof-of-concept trial. Diabetes Care. 2014;37(5):1480-1483.

66. Pieber TR, Famulla S, Eilbracht J, et al. Empagliflozin as adjunct to insulin in patients with type 1 diabetes: a 4-week, randomized, placebocontrolled trial (EASE-1). Diabetes Obes Metab. 2015;17(10):928-935.

67. Garg SK, Henry RR, Banks P, et al. Effects of sotagliflozin added to insulin in patients with type 1 diabetes. $N$ Engl J Med. 2017;377(24): 2337-2348.

68. Peters AL, Buschur EO, Buse JB, Cohan P, Diner JC, Hirsch IB. Euglycemic diabetic ketoacidosis: a potential complication of treatment with sodium-glucose cotransporter 2 inhibition. Diabetes Care. 2015;38(9):1687-1693.

69. Fadini GP, Bonora BM, Avogaro A. SGLT2 inhibitors and diabetic ketoacidosis: data from the FDA Adverse Event Reporting System. Diabetologia. 2017;60(8):1385-1389.

70. Rosenstock J, Ferrannini E. Euglycemic diabetic ketoacidosis: a predictable, detectable, and preventable safety concern with SGLT2 inhibitors. Diabetes Care. 2015;38(9):1638-1642.

71. Kuhadiya ND, Ghanim H, Mehta A, et al. Dapagliflozin as additional treatment to liraglutide and insulin in patients with type 1 diabetes. J Clin Endocrinol Metab. 2016;101(9):3506-3515.

72. Pettus J, Reeds D, Cavaiola TS, et al. Effect of a glucagon receptor antibody (REMD-477) in type 1 diabetes: a randomized controlled trial. Diabetes Obes Metab. Epub 2017 Dec 28.

73. Pearson MJ, Unger RH, Holland WL. Clinical trials, triumphs, and tribulations of glucagon receptor antagonists. Diabetes Care. 2016;39(7):1075-1077.

\section{Publish your work in this journal}

Diabetes, Metabolic Syndrome and Obesity: Targets and Therapy is an international, peer-reviewed open-access journal committed to the rapid publication of the latest laboratory and clinical findings in the fields of diabetes, metabolic syndrome and obesity research. Original research, review, case reports, hypothesis formation, expert opinion and commentaries are all considered for publication. The manuscript management system is completely online and includes a very quick and fair peer-review system, which is all easy to use. Visit http://www.dovepress.com/testimonials.php to read real quotes from published authors. 